\title{
Um olhar sobre o espaço destinado ao trabalho com gêneros do discurso em livros didáticos de língua portuguesa de ensino médio
}

\author{
Ana Paula Kuczmynda da Silveira \\ UFSC/IFSC
}

\begin{abstract}
Resumo
Este trabalho tem ancoragem da teoria dos gêneros do discurso (Bakhtin, 1997) e propõe-se a discutir o espaço destinado aos gêneros do discurso no âmbito de atividades voltadas ao ensino-aprendizagem de leitura e produção textual em dois livros de Língua Portuguesa destinados ao Ensino Médio.
\end{abstract}

Palavras-Chave: gêneros do discurso, leitura, produção textual

\begin{abstract}
This paper discusses the space for genres, based on genre theory (BAKHTIN, 1997), in the context of activities for the teaching and learning of reading and writing in two textbooks of Portuguese Language for high school students.

Keywords: genres, reading, writing
\end{abstract}

\section{REFLEXÕES INICIAIS}

A disciplina de Língua Portuguesa vem, ao longo dos últimos vinte anos, passando por modificações sensíveis implicadas pela redefinição dos parâmetros teóricos-metodológicos que norteiam o ensino-aprendizagem de língua materna, parâmetros esses apontados nas propostas curriculares municipais, estaduais e nos Parâmetros Curriculares Nacionais, os quais, com base em Geraldi (1984, 2002), sublinham a importância do trabalho com a língua em uso na sala de aula, contemplando a articulação das atividades de leitura, produção textual e análise linguística. Tais modificações apontam para a centralidade no trabalho com o texto vinculado à noção de gêneros do discurso, conforme proposta por Bakhtin (2003b).

O trabalho com o texto não constitui exatamente uma novidade no espaço das aulas de Língua Portuguesa, a novidade está na abordagem do texto e na própria concepção de sujeito, língua, texto e gênero que ancora esse trabalho. Isso porque o que se propõe não é o trabalho com o recorte, com o texto artificializado, “fabricado” para a sala de aula, descontextualizado, livre dos vínculos com a realidade, despido de marcas que nos permitem reconhecê-lo como efetivamente circula na sociedade. Também não nos referimos aqui ao trabalho com o texto 
como pretexto, o pretenso trabalho com o texto quando o que efetivamente se deseja é que se sublinhem palavras de determinada classe gramatical, ou que se classifiquem as palavras sublinhadas segundo a sua sílaba tônica. Ainda, não é a leitura para tentar se decifrar aquilo que pretensamente o autor quis dizer, ou ainda, a leitura como modelo para se produzir um outro texto, todas essas atividades bastante comuns nos livros didáticos há muitos anos. O que se deseja é o trabalho com textos que circulam na sociedade, e, como tal, medeiam interações reais, entre sujeitos sócio-historicamente situados, que fazem uso de uma língua viva e sóciohistoricamente constituída. Textos estes os quais constituem, eles mesmos, espaços de negociação de sentidos e que são produzidos, lidos e compreendidos sob a baliza dos gêneros do discurso.

Segundo Geraldi (2002), a produção do texto abre espaço à subjetividade, é o lugar em que o sujeito se compromete com suas palavras. Estabelecendo uma ponte com o pensamento bakhtiniano, pode-se compreender a produção textual como o lugar em que o sujeito revela a sua apreensão de mundo e se posiciona perante seu(s) interlocutor(es). A leitura representa “o espaço possível de respostas, de novas interpretações, de outros saberes que, confrontados com os seus, podem permitir novas descobertas.” (Britto, 2002:163). As descobertas se dão no confronto, no embate entre a visão de mundo que o leitor tem, os já-ditos que atravessam sua realidade, e aquilo que o texto, como enunciado, deixa transparecer. Por fim, a prática da análise linguística constitui a oportunidade da construção de um conhecimento adquirido no contato direto com o texto, na busca ou percepção de "recursos expressivos e processos de argumentação que se constituem na dinâmica da atividade linguística.” (Britto, 2002:164)

Pensar a redefinição do objeto de ensino da disciplina de Língua Portuguesa leva-nos a refletir sobre um dos materiais de mais forte influência na sala de aula: o livro didático (BRASIL, 1997), aprofundando uma pesquisa anterior (Silveira, 2008), em busca de perceber como se definem os pressupostos teórico-metodológicos que norteiam o trabalho com o texto no que concerne às particularidades do gênero do discurso em que ele (o texto) se inscreve: (1) no manual do professor e (2) no âmbito de atividades de leitura e produção textual.

Dentre os 12 livros recomendados para adoção na rede pública de ensino para o Ensino Médio (BRASIL, 2006), optamos por contemplar, no contexto desta pesquisa, dois "Português: Linguagens”, de William Roberto Cereja e Thereza A. C. Magalhães; e "Português - Língua e Cultura”, de Carlos Alberto Faraco. A escolha deveu-se ao fato de o primeiro constituir o livro didático mais adotado na rede pública de ensino e de o segundo apresentar uma abordagem diferenciada das questões contempladas pela disciplina de Língua 
Portuguesa, conforme apontado pelo próprio “Catálogo do Programa Nacional do Livro do Ensino Médio” (PNLEM) cujo objetivo é explicitar os critérios que balizaram o processo de avaliação dos livros, fornecer orientações para a escolha do livro a ser adotado em cada escola e enviar o formulário para que a escolha possa ser realizada (BRASIL, 2004). "Português Língua e Cultura”, de Carlos Alberto Faraco, ficou em quinto lugar entre os livros didáticos de língua portuguesa mais adotados em 2006 e em quarto lugar em 2008 (Base, 2008). Ambos os livros são edições em volume único, destinadas às três séries do ensino médio e englobam os conteúdos de Língua Portuguesa e Literatura Brasileira.

\section{O ESPAÇO DESTINADO AOS GÊNEROS DO DISCURSO NO MANUAL DO PROFESSOR}

Os livros aqui analisados, obedecendo a uma determinação do próprio MEC, constituem volumes únicos destinados às três séries do segundo grau, compreendendo a totalidade dos conteúdos relativos à disciplina de Língua Portuguesa e Literatura Brasileira e se organizam conforme apontamos no quadro a seguir (Quadro 1). Todavia, no caso do livro "Português: linguagens”, de William Roberto Cereja e Thereza A. C. Magalhães, também são disponibilizadas edições em três volumes - cada um destinado a uma série do ensino médio.

No caso de "Português: Língua e Cultura”, doravante PLC, o livro do professor distingue-se do livro do aluno pela presença do manual do professor, o qual constitui as primeiras 32 páginas do livro. No manual, o autor apresenta de forma sucinta os princípios teórico-metodológicos que ancoram a obra; traça considerações a respeito da utilização do livro em sala de aula, apontando seu papel como material de apoio ao professor, ao qual cabe determinar o sequenciamento que dará aos conteúdos a serem abordados e a maneira como fará uso do livro; realiza uma reflexão sobre avaliação e sobre a abordagem sugerida pelo livro para questões relativas à leitura, produção textual e para o ensino da gramática. O livro do professor não inclui respostas para os exercícios propostos, nem sugestões mais detalhadas para orientação do trabalho do professor, o que parece enfatizar o protagonismo do professor na elaboração didática dos conteúdos a serem abordados em sala de aula. 


\begin{tabular}{|c|c|}
\hline \multicolumn{2}{|c|}{ Organização geral da obra } \\
\hline $\begin{array}{l}\text { Português: Língua } \\
\text { e Cultura }\end{array}$ & $\begin{array}{l}35 \text { capítulos organizados em cinco diferentes blocos - } \\
\text { Bloco de Textos ( } 17 \text { capítulos); Enciclopédia da } \\
\text { Linguagem ( } 5 \text { capítulos); Almanaque Gramatical (4 } \\
\text { capítulos); Guia Normativo ( } 2 \text { capítulos) e História da } \\
\text { Literatura ( } 7 \text { capítulos) - e dois apêndices (um sobre } \\
\text { pontuação e outro sobre acentuação). } \\
9 \text { unidades constituídas por seis capítulos reunidos em } \\
\text { três grupos - Literatura, Língua: uso e reflexão, Produção } \\
\text { de texto. Ao final de cada unidade, há uma seção } \\
\text { denominada Intervalo, a qual se divide em duas partes - } \\
\text { imagem em foco e projeto. No interior de cada unidade } \\
\text { prevalecem, invariavelmente, os capítulos denominados } \\
\text { Literatura e Produção de texto. }\end{array}$ \\
\hline \multicolumn{2}{|l|}{ Gêneros estudados } \\
\hline $\begin{array}{l}\text { Português: Língua } \\
\text { e Cultura }\end{array}$ & $\begin{array}{l}\text { A seleção de textos compreende: crônicas, contos, } \\
\text { romances, poemas, notícias, reportagens, verbetes de } \\
\text { enciclopédia, entrevistas, editoriais, artigos e } \\
\text { propagandas impressas. } \\
\text { Ênfase dada aos gêneros da esfera literária, uma vez que } \\
\text { estes "têm maior permanência no tempo, organizam } \\
\text { esteticamente grandes questões humanas e a própria } \\
\text { linguagem verbal” (Faraco, 2005:04), aliada à presença } \\
\text { acentuada de gêneros da esfera jornalística. } \\
\text { O livro constitui parte de uma coleção destinada a } \\
\text { atender os alunos desde o } 1^{\circ} \text {. ano do ensino fundamental, } \\
\text { até o ensino médio, numa proposta de ensino em espiral. } \\
\text { Os gêneros abordados no âmbito de atividades de } \\
\text { leitura/escuta e produção textual compreendem (nas } \\
\text { palavras dos autores): o poema, o texto teatral, o relato, o } \\
\text { debate regrado, o texto argumentativo escrito, a notícia, a } \\
\text { reportagem, a crônica, a crítica, o editorial, o texto } \\
\text { publicitário, a carta argumentativa e o texto dissertativo- } \\
\text { argumentativo. }\end{array}$ \\
\hline
\end{tabular}

Quadro 1 - Organização das unidades no livro do aluno

Fonte: Dados de pesquisa

Já no que tange a "Português: Linguagens", doravante PL, o livro do professor traz respostas para os exercícios e apresenta, ao seu final, o manual do professor. Ao longo das 44 páginas que o constituem (o manual do professor), os autores discorrem sobre os fundamentos teórico-metodológicos da obra, sobre a maneira como ela se estrutura; apresentam sugestões de estratégias para o trabalho com as diversas unidades, o que inclui o trabalho com outros 
recursos além do livro didático; disponibilizam bibliografia destinada ao aprofundamento da leitura no que tange aos pressupostos teórico-metodológicos que ancoram a obra; apresentam sugestões específicas destinadas ao trabalho com os gêneros da esfera jornalística e um roteiro de perguntas para a análise de algumas obras literárias que o livro classifica como clássicos da literatura. Em ambas as obras, portanto, fica claro que os autores não compreendem o livro didático como único material a ser utilizado pelo professor nas aulas de Língua Portuguesa.

Atualmente o manual do professor de PL também é disponibilizado na internet e, ao apresentar o vídeo “Literatura e outras linguagens”, disponibilizado ao professor que adota a coleção para o Ensino Médio, esclarece que:

\begin{abstract}
Por meio de sugestões de filmes, músicas, sites e pesquisas, a obra já vinha, nas edições anteriores, estimulando professores e alunos a romper os limites estritos da palavra escrita e levar para o espaço da sala de aula a interação da linguagem literária com outras linguagens. Muitos professores, entretanto, alegando falta de tempo e condições para recolher, recortar ou preparar todo o material disponível, pediam aos autores que oferecessem um material audiovisual com muitas das sugestões feitas na obra.

O vídeo Literatura e outras linguagens pretende ser uma resposta a esse anseio do professor [..] (Cereja \& Magalhães, 2009:6)
\end{abstract}

No manual do professor de PLC, apesar de não citar diretamente Bakhtin ou os trabalhos do Círculo Bakhtin, nem mesmo entre as obras de referência para a leitura do professor, e de evitar, de certa forma, o uso do termo gênero do discurso, coisa que só faz uma vez ao longo de todo o manual do professor, Faraco (2005) assume a ancoragem em uma concepção sócio-histórica de linguagem, reafirma a centralidade no trabalho com o texto, vincula a produção e a leitura/escuta do texto à noção de gêneros do discurso e às particularidades da interação.

No que tange à concepção de língua, o autor afirma que esta constitui um "conjunto aberto e múltiplo de práticas sociointeracionais, orais ou escritas, desenvolvidas por indivíduos historicamente situados”, existente somente e efetivamente no contexto das relações sociais como "elemento constitutivo dessas múltiplas relações e nelas se constitui continuamente.” (Faraco, 2005:8, grifo nosso). Nesse sentido coaduna com Voloshinov/Bakhtin (2004:124) quando este afirma que “a língua vive e evolui historicamente na comunicação verbal”.

Ainda ao falar sobre a escrita, Faraco sublinha que “[...] a escrita cobra de nós uma ação de contínua adequação do nosso dizer às circunstâncias de sua produção.” (Faraco, 2005:8); o que está de acordo com a relação que Voloshinov/ Bakhtin (2004:113, grifo do autor) 
estabelece quando afirma que " $a$ situação social mais imediata e o meio social mais amplo determinam completamente e, por assim dizer, a partir do seu próprio interior, a estrutura da enunciação”, ou seja, o texto, aqui entendido como enunciado, é socialmente orientado.

Faraco também realça o papel do interlocutor na produção do texto quando afirma que “[..] escrevemos para alguém ler” e que “...o interlocutor é um dos condicionantes de nosso texto” (Faraco 2005:8), o que implica a orientação do texto para o outro de que fala Bakhtin (2003b). Todavia, é interessante ressaltar que no próprio manual do professor, ao falar desse outro, Faraco apenas menciona os colegas de classe e o próprio professor, o que se nos afigura como uma redução daquilo que propõe Geraldi (2002:136) quando estabelece a diferença entre produção de textos e redação, dizendo que: “nesta, produzem-se textos para a escola; naquela produzem-se textos na escola”, afirmando, assim, a necessidade de que a produção de textos na escola seja norteada pela relação interlocutiva, o que implica a produção de textos efetivamente direcionados a um interlocutor concreto.

Mais adiante, Faraco (2005:8) assinala que a escrita envolve entre outras ações operadas pelo autor “[...] adequar-se ao gênero, planejar o texto, organizar sua sequência, selecionar a variedade linguística, dialogar com os discursos que circulam socialmente.”. Nesse contexto, sublinha o fato de os gêneros agirem como baliza para a produção de sentidos, uma vez que, nas palavras de Bakhtin (2003b:282, grifo do autor), “a vontade discursiva do falante se realiza, antes de tudo na escolha de um determinado gênero do discurso.”, o que se vincula à adequação do texto aos parâmetros de cada interação específica. Assinala, ainda, o dialogismo no sentido de um diálogo amplo que se estabelece entre os discursos que circulam nas diversas esferas da atividade humana.

Também ao falar da leitura, a despeito da flutuação terminológica presente no manual, uma vez que Faraco (2005) utiliza o termo "tipos de texto”, para se referir ao que, de fato, constituem gêneros do discurso, aponta que “ler pressupõe, em primeiro lugar, familiarizar-se com diferentes tipos de textos oriundos das mais variadas práticas sociais. [...] perder a ingenuidade diante do texto dos outros, [...] implica reagir ao texto, dar-lhe uma resposta, [...].” (Faraco, 2005:6). Nesse contexto, assinala a postura responsiva do sujeito e sublinha que a resposta ao texto lido se constitui na confrontação desse texto com outros enunciados jáditos com os quais o sujeito dialogou anteriormente e que de uma ou outra maneira contribuíram para delinear o horizonte apreciativo a partir do qual o sujeito valora o texto lido.

Magalhães e Cereja (2003), apesar de fazerem referência explícita a Bakhtin em 
diversos momentos no "Manual do Professor", deixam clara a perspectiva a partir da qual percebem esses ditos: orientação interacionista e sociodiscursiva da Escola de Genebra representada por Schneuwly e Dolz (2004). É interessante observar, no manual do professor, algo que fica claro ao longo de todo o livro: os gêneros aparecem atrelados habitualmente, a atividades de produção textual, ainda que, nos capítulos denominados Produção textual, haja também atividades de leitura envolvendo, usualmente, um texto do mesmo gênero que aquele sugerido para balizar a atividade de produção textual.

Assim como em Faraco (2005), em Magalhães e Cereja (2003:18) fica evidente uma certa confusão terminológica acerca dos gêneros do discurso quando afirmam que: "Mikhail Bakhtin [...] foi o primeiro a empregar a palavra gênero com um sentido mais amplo [do que aquele utilizado pela retórica ou pela literatura], referindo-se também aos tipos textuais que empregamos nas situações cotidianas de comunicação.”. Como apontamos anteriormente, Bakhtin (2003b), ao fazer referências aos gêneros do discurso, não se referiu à noção de tipos de texto como tradicionalmente ela figura na literatura, ou seja, como "um esquema cognitivo que se compõe de partes características organizadas por uma sintaxe particular e está arquivado na memória de longo prazo do indivíduo para servir como recurso nas tarefas comunicativas nos sentidos de recepção e produção linguística” (Bonini, 1999:301), noção essa que também apresenta flutuações na literatura, mas referiu-se a um conjunto de parâmetros socio-historicamente construídos e mais ou menos estabilizados que caracterizam e diferenciam os textos que circulam nas diversas esferas da comunicação verbal, mediando as diferentes interações que nelas se efetivam.

Mais adiante, Magalhães e Cereja (2003:18) apontam que

segundo Bakhtin, todos os textos que produzimos, orais ou escritos, apresentam um conjunto de características relativamente estáveis, tenhamos ou não consciência delas. Essas características configuram diferentes tipos ou gêneros textuais, que podem ser identificados por três aspectos coexistentes: o assunto, a estrutura e o estilo (procedimentos recorrentes de linguagem).

Observam-se, no trecho citado acima, duas questões que nos parecem relevantes, a despeito da relação que os autores estabelecem entre os textos que produzimos e os gêneros que balizam essa produção: tomam-se tipos textuais e gêneros textuais (e não do gênero do discurso, como utilizado por Bakhtin) como sinônimos, e, em seguida, reduz-se conteúdo temático a assunto e construção composicional à estrutura, o que se configura, a nosso ver, como uma apreensão imprecisa do que diz Bakhtin (2003b).

Bakhtin (2003b) aponta que os enunciados refletem as condições particulares e 
finalidades de cada esfera da comunicação verbal tanto por seu conteúdo temático, quanto pelo seu estilo (escolha de recursos lexicais, fraseológicos e gramaticais da língua) e, sobretudo, por sua construção composicional, esta percebida como “determinados tipos de construção do conjunto, de tipos do seu acabamento, de tipos da relação do falante com os outros participantes da comunicação discursiva - com os ouvintes, os leitores, os parceiros, os discursos do outro, etc.” (Bakhtin, 2003b:266). No que se refere ao conteúdo temático, Bakhtin (2003b) o entende não como assunto, mas como objeto e finalidade discursiva que revela o querer-dizer do autor perante um dado auditório social, auditório este que orienta o autor/locutor na escolha de um gênero que seja apropriado à materialização de sua intenção discursiva.

\section{OS GÊNEROS DO DISCURSO EM ATIVIDADES DE LEITURA E PRODUÇÃO TEXTUAL}

A confusão terminológica à qual nos vínhamos referindo até agora parece ratificada mesmo na maneira como os autores nomeiam os gêneros com os quais irão trabalhar ao longo dos livros didáticos. Faraco (2005), ao longo dos primeiros capítulos do seu livro, parece balizar o trabalho que propõe realizar na noção de gênero do discurso, o que faz, por exemplo, ao propor o trabalho com a crônica ao longo dos dois primeiros capítulos do livro. Todavia, no capítulo 27, ao falar sobre o texto de opinião, reacende a chama da tipologia textual ao afirmar que:

Comecemos por dizer que boa parte dos textos de opinião recebe o nome técnico de texto dissertativo ou dissertação. Se num conto ou num romance, contamos uma história (isto é, fazemos uma narração), na dissertação defendemos uma opinião, um ponto de vista, uma tese; ou analisamos (refletimos sobre) as experiências humanas, ou apresentamos uma interpretação para um fato. (Faraco, 2005:418)

O comentário nos parece desnecessário e impreciso, pois, de fato, também em um romance podemos defender uma tese (como no romance de tese, comum no Realismo), assim como podemos escrever uma crônica, por exemplo, gênero que se situa na interface entre a esfera jornalística e literária, utilizando, predominantemente sequências narrativas, ainda que tenhamos o objetivo de defender um determinado ponto de vista ou refletir sobre as experiências humanas.

A mesma flutuação terminológica também se faz notar em PL. Note-se, por exemplo, que no capítulo 11, Magalhães e Cereja (2003) se propõem a abordar o texto argumentativo 
oral: o debate regrado. Da maneira como o gênero é apresentado, ele parece figurar como o único gênero que poderia se encaixar a tal classificação, ainda que na página 21 do manual do professor, ao se analisar um quadro reproduzido de Schneuwly e Dolz (2004), outros gêneros também sejam alinhados sob essa classificação. Fato semelhante ocorre quando se propõem a trabalhar o "gênero" texto argumentativo escrito, quando, na verdade, trabalham textos de diversos gêneros que têm, em comum, a mobilização da argumentação em benefício da defesa de um determinado ponto de vista.

Um exemplo do exposto acima é encontrado no capítulo 13 - Produção de Texto - O texto argumentativo escrito. Na seção trabalhando o gênero, é apresentado um texto para leitura e interpretação, retirado da revista Pais \& Teens. Segundo o livro, o texto foi escrito por um engenheiro de 48 anos e pai de três filhas, sobre o uso do piercing. No texto, o engenheiro dá sua opinião sobre o uso do piercing, respondendo à pergunta feita pela revista: “Body piercing: você deixaria seu filho usar?”. A atividade de leitura e interpretação, desenvolvida de maneira a chamar a atenção para a maneira como o autor mobiliza a sua argumentação, é bastante relevante e interessante; a questão aqui é que em virtude da maneira como o texto é apresentado (recortado do suporte, reformatado para ser publicado no livro didático), duas questões podem ser levantadas: (1) fica a impressão de que esse texto seria um exemplar do "gênero" texto argumentativo escrito, ou seja, dá a impressão de que o gênero efetivamente existiria; (2) o gênero que baliza a sua produção, em virtude da descaracterização operada pelo livro didático, acaba sendo dificilmente identificado; como em nenhum momento o livro menciona que ele foi escrito pelo engenheiro “a pedido” da revista, imagina-se que seja um artigo assinado, porém, ele poderia ter sido escrito para a seção cartas do leitor, como resposta a uma provocação feita pela revista (um questionamento lançado pela revista).

No capítulo 11 - Produção de Texto - O texto argumentativo oral: o debate regrado trabalha-se a reenunciação de um “debate regrado”, proposto pela revista Pais \& Teens, sobre “o que é ficar?”. Novamente, da maneira como a atividade é apresentada, fica a dúvida se o gênero trabalhado é o debate regrado, ou o texto argumentativo oral; ou ainda, se o debate regrado seria um exemplo ou o único exemplo de texto argumentativo oral. Mesmo que os autores estivessem pensando em trabalhar o debate regrado como gênero, é importante observar que o texto apresentado pelo livro (e também pela revista) não é um exemplar do gênero, mas, como dito antes, uma reenunciação de uma entrevista feita a um grupo de jovens com base em duas perguntas sobre o assunto já mencionado, questionamento esse que os 
levou a debater sobre o assunto. Em nenhum momento, é realçado o aspecto de que as falas dos jovens, ao serem reenunciadas pela revista, sofrem alterações.

No que se refere às atividades de leitura propostas pelos dois livros didáticos, é interessante observar que em PLC, as atividades relacionadas à prática de leitura e escrita concentram-se nos capítulos do bloco de texto. Tais capítulos iniciam com a apresentação de diferentes textos do gênero, cada qual seguido por uma seção denominada Estudo do Texto. Normalmente, há uma seção destinada a apresentar comentários mais aprofundados sobre o gênero e por fim, ao final do capítulo, procurando recuperar o conteúdo construído ao longo deste, há a sugestão de uma ou mais práticas de produção textual.

Parece-nos interessante a oferta de diversos textos do mesmo gênero seguidos de atividades que permitem, em alguma medida, perceber a maneira como tais gêneros se vinculam a características de ordem temática, composicional e estilística que se veem marcadas em tais textos. Contribuem também para isso os comentários apresentados pelo autor no que se refere a cada gênero específico; todavia, há que se ressaltar que, ainda assim, a abordagem realizada pelo livro carece de complementação por parte do professor, o que precisaria ocorrer ao longo de diversas elaborações didáticas focalizando um mesmo gênero. No caso da crônica, por exemplo, o livro didático (PLC) sinaliza apenas o uso de recursos relacionados ao humor para relatar, ou parodiar a vida real, o que exclui recursos, tais como a ironia e o sarcasmo, entre outros. Igualmente, a interlocução também fica na sombra; de fato, não há referências ao universo do cronista, a seu papel social, nem ao leitor previsto. De forma semelhante, apesar de o suporte de leitura onde o texto foi originalmente publicado ser mencionado, não há uma preocupação em se explorar o espaço de ancoragem do texto na esfera da comunicação verbal em que circula, assim não são feitas diferenças entre crônicas publicadas em livro, jornal impresso ou revista, o que assinala uma homogeneização da abordagem do gênero e enfraquece a sua vinculação fundamental a uma determinada prática social.

No que tange à produção textual, há, no final do primeiro capítulo, por exemplo, uma proposta não diretiva de escrever-se uma (ou várias) crônica(s) com base nos comentários traçados ao longo da análise dos textos do gênero utilizados nas atividades de leitura.

Vamos, então à nossa primeira prática de escrita! Propomos que você escreva uma crônica (ou várias). Quer dizer: relate por escrito uma (ou várias) dessas "histórias que a vida conta”.

As possibilidades são, obviamente, inúmeras. Lembre-se de que nossa memória está povoada dessas histórias: um acontecimento na rua, uma evento inesquecível de sua infância, um episódio numa atividade esportiva, um encontro inesperado e assim por diante.

Qualquer dessas histórias pode facilmente se tornar um texto bem interessante. E isso vai ficar logo evidente: observe como uns vão querer ler os textos dos outros. (Faraco, 2005:17). 
A proposta ilustra um posicionamento que se faz presente também no restante do livro no que tange à produção textual: (1) não são fornecidos ao aluno parâmetros que permitam vincular a produção do texto às especificidades da interação; (2) a produção textual toma como interlocutores apenas o professor e os colegas de classe. Isso implica um retorno ao paradigma da redação escolar produzida na escola e para a escola, que de certa maneira, já apontávamos na análise do manual do professor de PLC.

Em PL, Cereja e Magalhães (2003) propõem o trabalho com o gênero a partir da seguinte sequência de atividades: leitura e interpretação de um texto do gênero; comentários a respeito do gênero realçando aspectos principalmente vinculados à textualidade, em detrimento de aspectos relativos à interação (o que ocorre principalmente com gêneros da esfera jornalística como a reportagem, a notícia e a crônica); produção de um texto do gênero. Entendemos que a leitura de um único texto do gênero é insuficiente para que o aluno construa um conhecimento procedimental a respeito do gênero. Seria, pois, necessário, que o professor oportunizasse ao aluno a leitura de outros exemplares do gênero a fim de que esse conhecimento pudesse ser efetivamente construído de forma reflexiva e não apenas a partir das características alinhadas pelos autores do livro didático.

Quanto às atividades de produção de texto, é interessante apontar que, frequentemente, além da proposição de vários assuntos, os autores indicam passos a serem seguidos pelos alunos na elaboração do texto e assinalam o direcionamento do texto a outros interlocutores, além do professor e dos colegas de classe. Por exemplo, ao propor a produção textual de poemas, os autores apresentam quatro atividades e, em uma delas (na quarta), sugerem que:

Crie um ou mais poeminhas sobre o assunto que você quiser.

Ao terminar, troque o caderno com um colega: você lê os poemas dele e ele lê os seus, fazendo sugestões. Passe-os a limpo em folhas separadas, pendure-os no varal ou no mural da classe ou presenteie com eles um ou mais colegas. (Magalhães \& Cereja, 2003:47)

Também aqui é imprescindível o papel do professor para que, ao longo das diversas atividades de reescrita, o aluno possa se apropriar das particularidades do gênero.

\section{CONSIDERAÇÕES FINAIS}

A análise das obras didáticas que constituíram objeto desta pesquisa sugere que a indefinição terminológica que cerca a questão do gênero acarreta imprecisões conceituais, que 
podem prejudicar a elaboração didática do gênero para a prática de leitura/escuta e produção textual. Tais imprecisões podem provocar reduções, simplificações e generalizações que dificultam a apreensão do gênero e a compreensão da maneira como balizam a produção de textos, imprimindo-lhe características que dizem respeito ao estilo do gênero, sua dimensão temática e composicional.

Em ambos os livros, as atividades de produção textual são estimuladas a partir de práticas de leitura, entretanto, principalmente em LC, essas leituras parecem ser ofertadas em número insuficiente para que efetivamente o aluno possa aprender as particularidades do gênero. Ainda, em todos os casos, o descolamento do suporte em que circulou originalmente contribui para o apagamento de algumas particularidades da interação, a qual levou à escolha do gênero, principalmente no que diz respeito ao interlocutor do gênero e à esfera da comunicação verbal em que circula. Em ambas as obras é sempre a dimensão composicional do gênero que recebe mais atenção, sendo por vezes privilegiada, exclusivamente, a análise da organização textual.

No que tange ao conteúdo temático, principalmente em PL, este parece ser muitas vezes entendido como o assunto ao qual o texto remete, o que coaduna com a concepção de gênero às quais os autores fazem menção no manual do professor, desprezando-se sua finalidade discursiva e a sua orientação em relação à reação resposta-ativa do outro. A dimensão estilística do gênero é poucas vezes explicitada, principalmente em PL, dado o número reduzido de textos de um mesmo gênero. Uma maior variedade de textos permitiria ao aluno depreender determinadas regularidades no que se refere ao estilo daquele gênero.

\section{REFERÊNCIAS}

Bakhtin, M. M. (1997). Problemas da poética de Dostoiévski. Tradução do russo por Paulo Bezerra. 2. ed. rev. Rio de Janeiro: Forense Universitária.

\section{Editora da UNESP.}

(1998). Questões de literatura e de estética (a Teoria do Romance). 4. ed. São Paulo:

. (2003a). Apontamentos. In: Estética da Criação Verbal. São Paulo: Martins Fontes, $\underline{369-398}$.

. (2003b). Os gêneros do discurso. In: . Estética da Criação Verbal. São Paulo: Martins Fontes, 261-306.

. (2003c) O problema do texto na linguística, na filologia e em outras ciências humanas. 
In: Estética da Criação Verbal. São Paulo: Martins Fontes, 307-336.

Base. (2008). Ranking livro didático. Correio eletrônico. Curitiba.

Bonini, A. (1999). Reflexões em torno de um conceito psicolinguístico de tipo de texto. D.E.L.T.A., v. 15, n. 2, $\underline{301-318}$.

BRASIL. (1997) Parâmetros Curriculares Nacionais: Introdução aos Parâmetros Curriculares Nacionais. Brasília: SEF.

. (2004). Catálogo do Programa Nacional do Livro do Ensino Médio - PNLEM/2006: Língua Portuguesa. Brasília: SEF.

(2006). Orientações curriculares para o Ensino Médio - Linguagens, códigos e suas tecnologias. Brasília: SEF.

Britto, L. P. L. (2002). A sombra do caos: ensino de língua x tradição gramatical. São Paulo: Mercado de Letras.

Cereja, W. R. \& Magalhães, T. C. (2003). Português: Linguagens. São Paulo: Atual.

Cereja, W. R. \& Magalhães, T. C. (2009). Português: Linguagens - Manual do Professor. São Paulo: Atual, Disponível em: <http://www.editorasaraiva.com.br/atualeditora/pl/flippage/manualvolumeunico/>. Acesso em: 10/06/2010.

Dolz, J. \& Schneuwly, B. (2004). Gêneros e progressão em expressão oral e escrita elementos para reflexões sobre uma experiência suíça (francófona). In: Rojo, R. \& Cordeiro, G. S. (trad. e org.). Gêneros orais e escritos na escola. Campinas, SP: Mercado das Letras, 41-70.

Faraco, C. A. (2005) Português: língua e cultura. Curitiba: Base.

Geraldi, J. W. (1984). O texto na sala de aula - leitura \& produção. 3. ed. Cascavel: ASSOESTE.

. (2002). Portos de Passagem. 4. ed. São Paulo: Martins Fontes.

Silveira, A.P.K. da. (2008). A abordagem do gênero em dois livros didáticos de Língua Portuguesa destinados ao ensino médio. Working Papers em Linguística, vol. 9, no.1.

Volochinv, V. N. (2004). Marxismo e filosofia da linguagem: problemas fundamentais do método sociológico na ciência da linguagem. 11. ed. São Paulo: Hucitec.

\section{A AUTORA}

Ana Paula Kuczmynda da Silveira é professora do Instituto Federal de Santa Catarina (IFSC), no campus Gaspar, e doutoranda vinculada ao Programa de Pós-Graduação em Linguística Aplicada da Universidade Federal de Santa Catarina, onde realiza pesquisas na área de Linguística Aplicada.

e-mail: ana_paula_k.silveira@terra.com.br 